\title{
External Debt, Capital Flight and Political Risk
}

\section{Citation}

Alesina, Alberto, and Guido Tabellini. 1989. External debt, capital flight and political risk. Journal of International Economics 27(3-4): 199-220.

\section{Published Version}

doi:10.1016/0022-1996(89)90052-4

\section{Permanent link}

http://nrs.harvard.edu/urn-3:HUL.InstRepos:4553019

\section{Terms of Use}

This article was downloaded from Harvard University's DASH repository, and is made available under the terms and conditions applicable to Other Posted Material, as set forth at http:// nrs.harvard.edu/urn-3:HUL.InstRepos:dash.current.terms-of-use\#LAA

\section{Share Your Story}

The Harvard community has made this article openly available.

Please share how this access benefits you. Submit a story.

\section{Accessibility}


NBER WORKING PAPER SERIES

EXTERNAL DEBT, CAPITAL FLIGHT AND POLITICAL RISK

Alberto Alesina

Guido Tabellini

Working Paper No. 2610

NATIONAL BUREAU OF ECONOMIC RESEARCH

1050 Massachusetts Avenue

Cambridge, MA 02138

June 1988

We would like to thank the participants of the 1987 NBER Summer Institute and of seminars at the Federal Reserve Board, the University of Rochester, Georgetown University, M.I.T., Tel Aviv University, the University of Pittsburgh and Carnegie Mellon University for useful comments, Susanne Lohmann for excellent research assistance and the UCLA Academic Senate for financial support. We are responsible for any remaining mistakes. This research is part of NBER's research program in International Studies. Any opinions expressed are those of the authors and not those of the National Bureau of Economic Research. 
NBER Working Paper \#2610

June 1988

\section{EXTERNAL DEBT, CAPITAL FLIGHT AND POLITICAL RISK}

\section{Abstract}

This paper provides an explanation of the simultaneous occurrence of large accumulation of external debt, private capital outflow and relatively low domestic capital formation in developing countries. He consider a general equilibrium model in which two types of government with conflicting distributional goals randomly alternate in office. Uncertainty over the fiscal policies of future governments generates private capital flight and small domestic investment. This political uncertainty also provides the incentives for the current government to over accumulate externa 1 debt. The model also predicts that left wing governments are more inclined to impose restrictions on capital outflows than right wing governments. Finally, we examine how political uncertainty affects the risk premium charged by lenders and how debt repudiation may occur after a change of political regime.

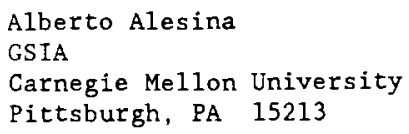

Guido Tabellini

Department of Economics University of California $405 \mathrm{Hilgard}$ Avenue Los Angeles, CA 90024 


\section{Introduction}

In the seventies and eighties, while the public sectors of many developing countries were accumulating large external debts, the private sectors of those same countries were accumulating large external assets. 1 The extent of this phenomenon is documented in Table 1 . It is most evident in Argentina, Mexico, Venezuela, Uruguay, and to a lesser extent in Peru and the Philippines. Massive capital outflows also occurred in Peru and Chile in the early 1970s, which are not included in Table 1 (see Ascher (1986)). In addition, Dornbusch (1986) emphasizes that large accumulation of imported durable consumption goods in Chile in 1979-82 had the same effects of capital flight. 2 Domestic investment in productive capital in all of these countries has generally declined, particularly from the late seventies onward. 3

Because of the adverse terms of trade shocks of the late 1970 s and early 1980s, this peculiar intermediation by the U.S. banks has contributed to expose the Latin American public sectors to very high real interest rates (evaluated in domestic currencies). Moreover, since the private external assets are generally not being repatriated, the Latin American economies had to undergo tremendous adjustments to generate the foreign exchange needed to service their debt, as Diaz Alejandro (1984), Dornbusch (1986) and Edwards (1987) pointed out.

This paper seeks to explain this apparent form of collective irrationality as the result of political polarization and political instability. It also suggests why several governments did not attempt to prevent these capital flights, by imposing restrictions on capital outflows, by avoiding sharp appreciations of their exchange rates and by restricting their own public external borrowing. This behavior is explained as the rational response of policymakers who maximize the welfare of their own constituency or social group as opposed to collective welfare, in economies politically and socially polarized. 4

We consider an economy with two groups of agents identified by their productive role: the "workers" (wage earners) and the "capitalists" (owners of physical capital and profit earners). The two groups have their own political representatives ("parties") that alternate in office. Although this is a highly stylized characterization of the political arena, it certainly captures some important aspects of the politico-economic structure of 


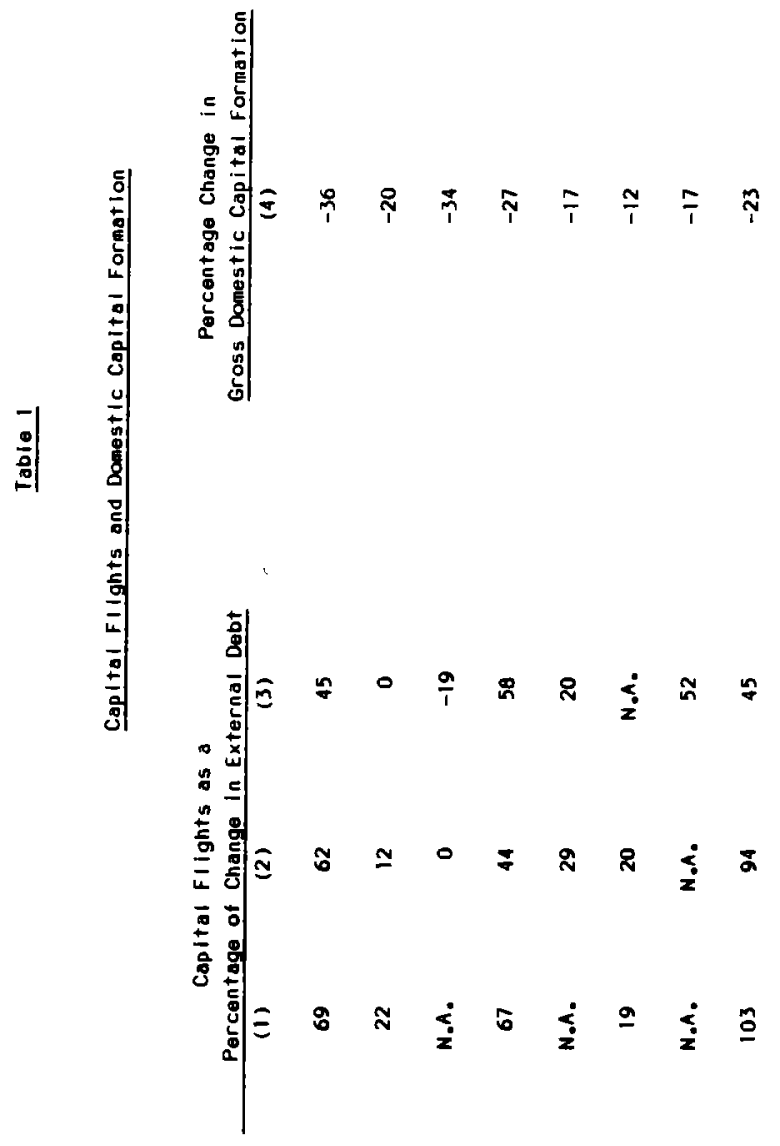

올

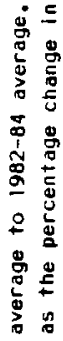

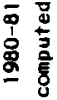

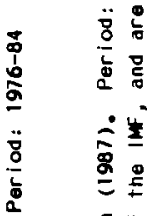

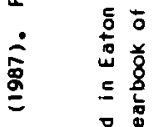

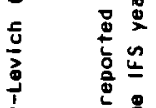

है

วิ ฐ

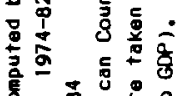
总

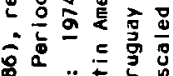

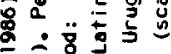

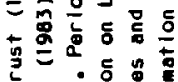

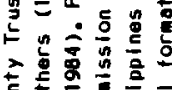

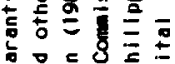
矛它

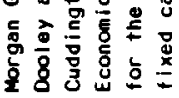
ఏลิิ

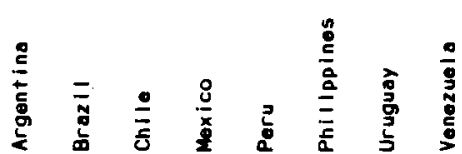

㫄 
developing countries. Each government implements policies that are beneficial for its own group. We consider in particular fiscal policies, even though in a more general setting additional policy instruments could be considered, such as monetary and exchange rate policies.

The purpose of the fiscal policy of the party in office is to redistribute income in favor of its own constituency. Thus, if these policies are sucessful, one should observe that the distribution of income is correlated to the political orientation of the government. Tables 2 and 3 , which are based upon different statistical sources, show that this may in fact be the case at least in four counitries, Argentina, Chile, Peru and Uruguay. These countries have been selected from the larger sample of Table 1 because they have experienced the more clearly identifiable changes of regimes in the period in which reliable data are available. Both tables show that left wing governments have generally increased the labor share of national income, and reduced the operating surplus; the opposite holds for right wing regimes. Table 4 reports an indirect piece of evidence along the same line. It shows that minimum wages have been much higher (lower) during left wing (right wing) regimes.

Broadly speaking, these tables suggest that ideological polarization has been associated with polarization of redistributive policies. Thus, political uncertainty about the nature of future governments generates economic uncertainty about future economic policies. Private capital fiight is explained in this paper as an insurance against the risk of future taxation, as in Khan-Haque (1986), Eaton (1987), Eaton-Gersovitz (1987) and Giovannini (1988). We then show that the desirability of capital controls depends on the political nature of the government: the government representing the capitalist constituency never finds it optimal to impose capital controls; converseiy, the government representing the interests of the worker aiways imposes some restrictions on capital outflows, even if they are binding on capitalists as well as on workers.

Political uncertainty also explains the accumulation of external debt above the social planner's optimum. Overborrowing occurs if the current government does not fully internalize the future costs of servicing the debt. Consider, for instance, the case in which both governments tax their opponents at the maximum feasible level in order to redistribute to their own constituency. The government which currentiy borrows, say the "capitalist" 
TABLE 2

Income Distribution and Political Regimes

Source: United Nations

\begin{tabular}{|c|c|c|}
\hline & $\begin{array}{l}\text { Ratio of } \\
\text { Compensation of } \\
\text { Employees Over } \\
\text { GDP (averages) }\end{array}$ & $\begin{array}{c}\text { Ratio of } \\
\text { Operating Surpius } \\
\text { Over GDP } \\
\text { (averages) }\end{array}$ \\
\hline \multicolumn{3}{|l|}{ Argentina } \\
\hline 1970-72 Right & .44 & .44 \\
\hline 1973-75 Left & .44 & .47 \\
\hline 1976-83 Right & .31 & .57 \\
\hline \multicolumn{3}{|l|}{ Chile } \\
\hline 1971-73 Left & .45 & .37 \\
\hline 1974-84 Right & .39 & .36 \\
\hline \multicolumn{3}{|l|}{$\underline{\text { Peru }}$} \\
\hline 1970-76 Left & .37 & .50 \\
\hline 1977-84 Right & .32 & .53 \\
\hline \multicolumn{3}{|l|}{ Uruguay } \\
\hline 1970-72 Left & .43 & .39 \\
\hline 1973-76 Right & .40 & .43 \\
\hline 1977-81 Center/Right & .32 & .49 \\
\hline
\end{tabular}

Source: United Nations, National Account Statistics: Main Aggregates. The classification of political regimes is obtained from Banks (1986). 
Table 3

Income Distribution and Political Regimes

National Sources

\section{Labor Share}

(1)

Argentina

1967-72 Right

1973-75 Left

Chile

1969-72 Left

1974-82 Right

\section{Peru}

1970-76 Left

1977-79 Right

Uruguay

1967-72 Left

1973-76 Right

1976-84 Center/Right
.41

.45

N.A.

N.A.

.56

.39

.45

.42

.43

.58

.40

.66

.48

.41 (ii)

.50 (i)

.51 (ii)

.35

(1) Labor share defined as compensation of employees over national disposable incone.

(2) Capital share defined as operating surplus over national disposable income.

(i) 1970 only

(ii) Average 1975-76

Sources: Statistical Abstract of Latin America, Vol. 21, Chapter 14, Table 1404; 8anco Central de Chile, 8oletin Mensuel (various issues); Instituto National de la Pianification: "Cuentos Nacionales del Peru" July 1980 (Table 8 p. 82); Central Bank of Uruguay, Summary of National Statistics. 


$$
\text { Table } 4
$$

$$
\begin{aligned}
& \text { Index of Minimum Real Wage (non-agricultural) } \\
& \text { and Political Regimes }(1970=100)
\end{aligned}
$$

\section{Averages}

$\begin{array}{lccc} & \text { Right } & \text { Left } & \text { Right } \\ & 1967-72 & 1973-75 & 1976-80 \\ \text { Argentina } & 92.2 & 116.7 & 51.2 \\ & \text { Left } & & \\ & 1967-73 & \text { Right } & \\ \text { Chile } & 92.6 & 1973-80 & \text { Right } \\ & & 72.1 & 1977-80 \\ & \text { Right } & & 92.4 \\ \text { Peru } & 1967-68 & \text { Left } & \\ & 90.5 & 1969-76 & 97.9 \\ & & & \end{array}$

Source: Statistical Abstract of Latin America, Vol, 24, Ch. 14, Table 1407. 
one, knows that with some probability the debt will be serviced in the future by the workers government, by reducing transfers to the workers. Since these costs are not internalized, the capitalist government overborrows. The capitalists use their increased disposable income to consume and optimally allocate their savings between external assets and domestic investment. Thus, political polarization leads at the same time to overaccumulation of public debt and private capital fight. 6

These results hold even if each government has the option of repudiating the debt inherited by its predecessor. Following Cohen-Sachs (1985) and Sachs (1985) we model reputation costs as a loss to the country's output. ${ }^{7}$ In addition we consider the possibility that the external assets held by the citizen of the defaulting government may be seized. These repudiation costs have redistributional implications and they are perceived differently by the two types of government. As a result, repudiation can be observed in equilibrium if the government which suffers less from repudiating the debt unexpectedly gains access to office and if the outstanding external debt is high enough. In particular, if one of the costs of defaulting is the seizure of private external asset held abroad, then it is less costly for left wing governments to repudiate; under this assumption one prediction of the model is that one is more likely to observe debt repudiation if a left wing government unexpectedly gains office. This result is consistent with the empirical observation that left-wing governments have been more outspoken in criticizing IMF adjustment plans which attempt to guarantee the solvency of debtor countries. 8 Note that, since the interest rate demanded by the lenders correctly takes this political risk into account, this paper establishes a precise link between the cost of external borrowing, the risk of debt repudiation and political risk.

The explanation for private capital outflows given in this paper is meant to be a complement (rather than an alternative) to the explanation based upon the risk of expected devaluation of the exchange rate as in Dornbusch (1985) and Cuddington (1985). We also do not exclude that "policy mistakes" and "mismanagement", in addition to political instability, may contribute to explain excessive government borrowing and private capital flight as emphasized for instance by, Sachs (1985), Dornbusch (1986, 1987) and Dornbusch - de Pablo (1987).

The paper is organized as follows. Section 2 describes the model. 
Section 3 characterizes the equilibrium, shows the coexistence of public borrowing and private capital flights and establishes several results of comparative statics. Section 4 discusses capital controls. Section 5 extends the model by considering endogenous default risk. The main results of the paper are summarized in the conclusions.

\section{The Model}

We consider a small open economy producing one good with two groups of agents, the "workers" and the "capitalists". The workers supply inelastically one unit of labor in each period of their life and are prevented from acquiring shares of capital: they cannot become capitalists. The assumption about labor supply can be easily generalized: since the qualitative features of our results remains unaffected we present the simpler case. ${ }^{9}$ The "capitalists" own the capital stock and hire labor. The production technology of each capitalist is given by a production function:

$$
Y_{t} \equiv F\left(K_{t}, L_{t}\right)
$$

where: $Y_{t} \equiv$ output in period $t ; K_{t} \equiv$ capital stock at the beginning of period $t$; $L_{t} \equiv$ employment in period $t . F(\cdot)$ is homogeneous of degree 1 . We set $L_{t}=1$, so that (1) can be rewritten as:

$$
y_{t}=f\left(k_{t}\right)
$$

Letting $w_{t}$ denote the wage we obtain:

$$
w_{t}=f\left(k_{t}\right)-f^{\prime}\left(k_{t}\right) k_{t}
$$

where lower case letters denote units per worker. Without loss of generality, we assume that the stock of capital does not depreciate, and $k_{1}$, the stock of capital at the beginning of period 1, is exogenously given. The economy lasts two periods. The qualitative results of this paper can be generalized (at least for some specification of the utility functions) to the infinite horizon case, by using the same dynamic programming solution described in Alesina Tabellini (1987). 
The "representative worker" maximizes his expected utility function:

$$
E\left[u\left(c_{1}\right)+B u\left(c_{2}\right)\right]
$$

subject to the following budget constraints:

$$
\begin{aligned}
& c_{1} \leq w_{1}\left(1-\tau_{1}\right)+g_{1}^{w}+e^{w}-\frac{1}{1+r} b_{2}^{w} \\
& c_{2} \leq w_{2}\left(1-\tau_{2}\right)+g_{2}^{w}+b_{2}^{w}
\end{aligned}
$$

where: $\quad c_{j}=$ worker's consumption in period $i_{;} \tau_{j} \geq 0$, taxes on labor income in period $i ; g_{j}^{W} \geq 0$ government transfers to the worker in period $i ; b_{2}^{W}=$ external assets (tax exempt) held by the worker at the beginning of period 2; $e^{w}=$ tax exempt non-storable endowment available to the worker at the beginning of period $1 ; r=$ world real interest rate. The function $u(\cdot)$ satisfies the usual properties, $u^{\prime}(\cdot)>0$ and $u^{\prime \prime}(\cdot)<0$, plus the Inada conditions. We also assume that the rate of time preference is identical to the interest rate, $r$, so that:

$$
B=\frac{1}{1+r} \text {. }
$$

This assumption is adopted purely for simplicity, to eliminate any additional incentive to borrow or lend other than those which are the focus of the present paper. In particular, this assumption implies that a "social planner" would not borrow abroad to redistribute domestic consumption over time.

The "representative capital ist" maximizes his expected utility function:

$$
E\left[v\left(x_{1}\right)+\operatorname{sv}\left(x_{2}\right)\right]
$$

Using (7) the budget contraints can be written as:

$$
\begin{aligned}
& x_{1} \leq\left(f\left(k_{1}\right)+k_{1}-w_{1}\right)\left(1-z_{1}\right)-k_{2}-s b_{2}^{c}+e^{c}+g_{1}^{c} \\
& x_{2} \leq b_{2}^{c}+\left(f\left(k_{2}\right)+k_{2}-w_{2}\right)\left(1-z_{2}\right)+g_{2}^{c}
\end{aligned}
$$

where: $x_{i}=$ capitalist consumption in period $i ; z_{i}=$ taxes on capital and 
capital income; $b_{j}^{C}=$ external assets (tax exempt) of the capitalist at the beginning of period $i ; g_{i}^{c} \geq 0$ government transfers to the capitalist; $e^{c}=$ tax exempt nonstorable endowment available at the beginning of period 1.10

The function $v(\cdot)$ satisfies the usual properties, $v^{\prime}(\cdot)>0$ and $v^{\prime \prime}(\cdot)<0$, and the Inada conditions.

With no loss of generality we assume that at the beginning of period 1 both workers and capitalists do not have assets or liabilities abroad, i.e., $b_{1}^{w}=b_{1}^{c}=0$. However, both workers and capitalists have a positive tax exempt endowment. This makes the first period problem more interesting: both capitalists and workers have some income which cannot be expropriated and allows them to make investment/consumption decisions. Finally, the case in which workers have no access to international capital markets can be easfly addressed as a special case of this model. 11

The government can raise taxes, borrow abroad and make lump sum transfers to its citizens, while lump sum taxes are unavailable. With no loss of generality we assume that there are no public goods to be supplied. We also assume, for simplicity, that the government does not issue domestic bonds. In Section 3 we argue that our results generalize to the case in which the government could choose to borrow domestically. Thus given (7) the budget constraints of the government are:

$$
\begin{aligned}
& g_{1}^{c}+g_{1}^{w}+\leq \tau_{1} w_{1}+z_{1}\left(k_{1}+f\left(k_{1}\right)-w_{1}\right)+s d_{2} \\
& g_{2}^{c}+g_{2}^{w} \leq \tau_{2} w_{2}+z_{2}\left(k_{2}+f\left(k_{2}\right)-w_{2}\right)-d_{2}
\end{aligned}
$$

where $d_{2}=$ external debt issued by the government in period 1 .

Throughout the paper we assume that the government cannot borrow more than a certain amount, $\bar{d}$ :

$$
d_{2} \leq \bar{d}
$$

For the moment, the credit limit $\bar{d}$ is assumed to be exogenous and identical for the two governments. In Section 6 it is endogenously derived when we explicitly consider the possibility of repudiation: Until then we assume no repudiation.

The government can be of two types: type "w", that maximizes the workers" 
welfare (equation (4)); and type " $c$ ", that maximizes the capitalists" welfare (equation (10)). Irrespective of which government is in office in period 1 , type $c$ is in office in period 2 with probability $P$ and type $w$ with probability 1-P. $P$ is exogenously given throughout this paper. If the country is a democracy, we can interpret this assumption as follows. There are elections at the end of period 1 and the (rational) voters vote for the party which is expected to deliver the highest utility for themselves in period 2 . The distribution of preferences of voters and/or the number of abstentions determines the probabilistic result. Alesina (1988a) and Alesina-Tabellini (1987) show in a related context how to endogenously derive $P$ from the underlying preferences of voters. If the country considered is not a democracy, $P$ represents the likelihood that, say, type "w" government is overthrown by type " $c$ " government. The likelihood of overthrowing a non denocratic government may be affected by current and expected economic outcomes; however this link is not considered in this paper.

\section{Public External Debt and Private Capital Flights}

First we characterize the behavior of workers and capitalists by solving their optimization problems and taking the government actions as given. In order to simplify the solution we establish the following result.

If :

$$
\bar{d} \leq \operatorname{Min}\left[w_{2}, f\left(k_{2}\right)+k_{2}-w_{2}\right]
$$

then it follows that $\tau_{i}=g_{i}^{c}=0$ and $z_{i}=1$ if type " $w$ " is in office in period $i$, for $i=1,2$. $z_{i}=g_{i}^{W}=0$ and $\tau_{i}=1$ if type " $c$ " is in office in period $i$, for $1=1,2$.

Thus, if the workers are in office they expropriate the capitalists and do not tax labor, and vice versa. In addition, each government does not make any transfers to its opponent's constituency. This result follows from the fact that each government does not attribute any weight to its opponent constituency and from the fact that, ex-post, the taxes of this model are nondistortionary. The labor income tax is non distortionary because the labor supply is inelastic. The capital income tax is non distortionary ex-post since, in period $2, k_{2}$ is predetermined: this is the well known result that the optimal tax or capital is time inconsistent, as discussed in more detail 
by Fischer (1980). If the labor supply were elastic, the capitalist government would not choose $\tau_{1}=1$. The " $c$ " government would never choose a tax rate in the negative part of the Laffer curve: they would choose the tax rate which maximizes tax revenue; In genera1, this tax rate lies between zero and 1.

Condition (14) implies that each government is always able to repay its external debt in full without taxing its own group. Otherwise, if in period 2 , say, type " $c$ " is in office, it sets $\tau_{i}=1, g_{2}^{w}=0$ and $z_{2}$ equal to the minimum value necessary to satisfy the government budget constraint. If (14) holds, this value of $z_{2}$ is zero. Thus, condition (14) is adopted purely for notational simplicity: it does not affect the nature of the results in any respect.

The workers' optimization problem can then be rewritten as follows:

$$
\begin{aligned}
& \operatorname{Max} u\left(c_{1}\right)+\beta\left[P u\left(b_{2}^{w}\right)+(1-P) u\left(w_{2}+b_{2}^{w}+g_{2}^{w}\right)\right] \\
& c_{1}, b_{2}^{w}
\end{aligned}
$$

subject to (5). The first order condition is:

$$
-u^{\prime}\left(c_{1}\right)+P u^{\prime}\left(b_{2}^{w}\right)+(1-P) u^{\prime}\left(w_{2}+g_{2}^{w}+b_{2}^{w}\right)=0
$$

By the Inada conditions on $u(\cdot),(17)$ implies that, if $P<1$, then the workers hold some external assets, $b_{2}^{w}>0$.

Using (8) - (10), we can rewrite the capitalists' problem as:

$$
\begin{aligned}
& \operatorname{Max} v\left(x_{1}\right)+\beta\left[P v\left(b_{2}^{c}+k_{2}+f\left(k_{2}\right)-w_{2}+g_{2}^{c}\right)+(1-P)\left(v\left(b_{2}^{c}\right)\right]\right. \\
& x_{1}, b_{2}^{c}, k_{2}
\end{aligned}
$$

subject to (9). The first order conditions are:

$$
\begin{aligned}
& -v^{\prime}\left(x_{1}\right)+(1-P) v^{\prime}\left(b_{2}^{c}\right)+P v^{\prime}\left(b_{2}^{c}+k_{2}+f\left(k_{2}\right)-w_{2}+g_{2}^{c}\right)=0 \\
& -(1-P) v^{\prime}\left(b_{2}^{c}\right)+P v^{\prime}\left[b_{2}^{c}+k_{2}+f\left(k_{2}\right)-w_{2}+g_{2}^{c}\right]\left[\beta\left(1+f^{\prime}\left(k_{2}\right)-1\right]=0\right.
\end{aligned}
$$

According to (19), if $P>0$, then the capitalists hold external assets $\left(b_{2}^{c}>0\right)$ and the rate of return on domestic capital exceeds the world real rate of interest i.e. $\left(B\left(1+f^{\prime}\left(k_{2}\right)\right)>1\right)$. Thus, political uncertainty 
generates capital flight and reduces domestic capital formation.

Let us now turn to the governments' problem. In the last period the government's optimization problem is very simple. If the type c government is in office it sets $z_{2}=g_{2}^{W}=0$ and $\tau_{2}=1$. With the tax revenues it services the debt inherited from the past (if any) and uses the residual to make a transfer to the capitalists $\left(g_{2}^{C}>0\right)$. The type $w$ government behaves in the opposite way; $\tau_{2}=g_{2}^{c}=0, z_{2}=1, g_{2}^{W}>0$.

Let us now consider the problem faced by the "c" government in period 1. By using the result just established and by substituting the government's budget constraint into the objective function, we can rewrite the " $c$ " government problem as follows:

$$
b_{2}^{c}, k_{2}, d_{2}, b_{2}^{w}
$$

subject to (13) and the private sector's first order conditions, (17), and (19). Define $r$ as the Lagrange multiplier associated with the government borrowing constraint, (13). Appendix 1 shows that the first order conditions of this problem imply:

$$
\gamma=\beta V^{\prime}\left(x_{1}\right)-\beta P V^{\prime}\left(f\left(k_{2}\right)+k_{2}+b_{2}^{c}-\bar{d}\right)
$$

Using (19a) and (21) it follows that

$$
\gamma=(1-P) v^{\prime}\left(b_{2}^{c}\right)
$$

Thus, if $P<1$ then $\gamma>0$ and as a result $d_{2}=\bar{d}$. The government is at a corner on its external debt: it would like to borrow more but it is rationed by the market. Equation (21) provides the intuition for this result. The first term on the right hand side, $B V^{\prime}\left(x_{1}\right)$, is the marginal gain of issuing one more unit of government debt, evaluated in terms of period 1 utility: by issuing one more unit of external debt, the government obtains an amount $\beta$ of real resources which can be transferred to the capitalists, yielding a marginal utility of $v^{\prime}\left(x_{1}\right)$. The second term on the right hand side of (21), $-B P v^{\prime}\left(f\left(k_{2}\right)+k_{2}+b_{2}^{c}-\bar{d}\right)$, is the expected marginal disutility of repaying the debt tomorrow, discounted to the present by $B$. Specifically, it is the 
marginal disutility of curtailing the transfers to the capitalists, $\beta v^{\prime}(\cdot)$, weighted by the probability $P$ of being in office tomorrow. If the " $c$ " government type is not reappointed tomorrow, then the marginal disutility of debt is zero, since the capitalists would receive no transfer anyway, irrespective of the size of the debt. Thus (21) implies that the shadow value of relaxing the government borrowing constraint, $\gamma$, is equal to the algebraic sum of the marginal utility of issuing public debt today and the expected marginal disutility of repaying it tomorrow. Equation (22) shows that this sum is always positive if $P<1$.

We can summarize this discussion in the following:

Proposition 1:

If $1>p>0$, then type $c$ government sets: $d_{2}=\bar{d}, z_{1}=g_{1}^{W}=0, \tau,=1, g_{1}^{c}>0$

The capitalists and the workers in turn set: $x_{1}>0, b_{2}^{c}>0, k_{2}>0 ; c_{1}>0, b_{2}^{W}>0$.

The type " $c$ " government borrows from abroad as much as it can, in order to increase current transfers to the capitalists. The latter, in turn, optimally use these transfers to a) increase consumption, b) acquire foreign assets sheltered from fiscal expropriation, c) increase domestic investment. Thus, in equilibrium, the government borrows from abroad while the private sector acquires foreign assets, despite the fact that they face the same worid interest rate.

Note that Proposition 1 hinges on the fact that the two governments are always a corner with respect to tax rates and transfers: for instance, if elected in period 2, the workers government sets $z_{2}=1$ and chooses $g_{2}^{W}$ so as to satisfy the government budget constraint. Thus, any change in external debt inherited from the past affects the size of transfers but not the level of taxation, which is always at its maximum. This feature of the equilibrium follows from the extreme preferences of the two governments: they only care about one group, and completely disregard the second group. The same result could also be easily derived from less extreme assumptions about the government preferences, as long as the political and administrative costs of changing taxes are larger than those of changing the size of the transfers. (See also Alesina-Tabellini (1987) for some discussion of this point in a related framework). 
If the type $w$ government is in office in period 1 it faces the following problem:

$$
d_{2}, b_{2}^{W}, k_{2}, b_{2}^{c} u\left(k_{1}+e^{w}+f\left(k_{1}\right)+B d_{2}-B b_{2}^{w}\right)+\beta\left[P u\left(b_{2}^{w}\right)+(1-P) u\left(k_{2}+f\left(k_{2}\right)+b_{2}^{W}-d_{2}\right]\right.
$$

subject to (13) and the private sector's first order conditions, (17), (19) and (20). Appendix 2 shows that, by the same argument used for the type $c$ government, the equilibrium is characterized by:

\section{Proposition 2}

If $1>P>0$, the the type $w$ government sets: $d_{2}=\bar{d}, \tau_{1}=g_{1}^{c}=0, z_{1}=1, g_{1}^{W}>0$

The workers and the capitalists in turn set: $\quad x_{1}>0, b_{2}^{c}>0, k_{2}>0, c_{1}>0, b_{2}^{W}>0$.

Thus, as in the previous case, the government accumulates as much external debt as it can, and the private sector insures itse if against future expropriation by holding external assets. The intuition is also the same as above.

It can be shown (the proof is available upon request) that if the workers had no access to the international financial market (i.e., if we impose the constraint $b_{2}^{w}=0$ ), then in equilibrium we would obtain

$$
\bar{d} \geq d_{2}>0
$$

The reason is that, if $b_{2}^{w}=0$, the workers cannot smooth consumption across time. Thus, their government would not want to tilt their consumption profile too much: an excessive public borrowing in period 1 could imply a an excessively low expected consumption in period 2 . Thus, the type $w$ government would not necessarily borrow as much as possible in period 1.

Finally, several comparative static results can be estabiished. By applying the implicit function theorem to the first order conditions of the governments' optimization problem, the following results can be proved: 


\section{Proposition 3:}

Irrespective of which government is in office in the first period:

$$
\begin{aligned}
& \frac{\partial k_{2}}{\partial \bar{d}}>0 \quad \frac{\partial b_{2}^{W}}{\partial \bar{d}}>0 \\
& \frac{\partial k_{2}}{\partial P}>0 \quad \frac{\partial b_{2}^{W}}{\partial P}>0 \quad \frac{\partial b_{2}^{C}}{\partial P}<0 \\
& \frac{a b_{2}^{c}}{a d}>0 \quad \text { if type } c \text { is in office in period } 1 \\
& \frac{\partial b_{2}^{C}}{\partial \bar{d}}>0 \quad \frac{\text { if type } w \text { is in office in period } 1 \text {, depending on }}{\text { parameter values }}
\end{aligned}
$$

The proof is in Appendix 3.

Proposition 3 highlights that an increase in the political risk faced by the capitalists (i.e., a reduction of $P$, ) reduces domestic investment and leads to more capital flights by the capitalists. However, for the same reasons, a reduction in $P$ reduces the capital flights of the workers. Under the realistic assumption that the capital flights of "workers" are much sialler than those of the capitalists, Proposition 3 implies that capital flight should be particularly high when right wing regimes are expected to collapse (and at the beginning of left wing regimes before the new capital taxation is implemented).

Proposition 3 also implies that relaxing the government borrowing constraint (i.e., increasing $\bar{d}$ ), leads to more domestic investment but it can also lead to more capital flight. This implies, for instance, that if the intervention of international organizations such as the World Bank or the IMF in the world financial markets enables the government of this developing country to borrow more, one should observe an increased volume of capitai flight away from this country.

Before closing we argue that the basic results of this section also apply to a model with domestic government debt. Suppose first that domestic debt is taxable, like domestic capital. Thus, from the point of view of the public, 
domestic debt is an asset subject to political risk. For this reason, capital flight would still occur in period 1 as an insurance against risk. In addition a "risk premium" would be demanded to hold domestic debt. Since the governments in period 1 are at a corner, in the sense that they would like to redistribute to their constituency as much as they can, they would still borrow abroad up to d (at the risk free interest rate). In addition, they may go beyond this point and issue some domestic debt. Consider instead the case in which a certain amount of domestic debt cannot be expropriated and has to be serviced. Then up to that level, domestic government debt becomes a perfect substitute of external asset for the public in the first period. Depending upon the relative magnitude of the "safe" domestic debt relative to the size of the investment in safe assets desired by the public, private agents may hold external assets or external liabilities.

\section{Capital Controls}

Suppose that the private acquisition of foreign assets can be constrained by the government in a non discriminatory fashion; namely the constraint must be the same for every individual. Hence, we add the following constraints to the private sector optimization problems:

$$
b_{2}^{w} \leq q \quad, \quad b_{2}^{c} \leq q
$$

where $q \geq 0$ is the limit to foreign assets holding allowed by the governiment. Whenever these constraints are binding, the first order conditions of the capitalists can be obtained by solving problem (18) with the additional constraint (25). These conditions are:

$$
\begin{aligned}
& -v^{\prime}\left(x_{1}\right)+(1-P) v^{\prime}(q)+P v^{\prime}\left(f^{\prime}\left(k_{2}\right)+k_{2}+q-d_{2}\right)-\eta^{c}=0 \\
& -(1-P) v^{\prime}(q)+\pi^{c}+P v^{\prime}\left(f^{\prime}\left(k_{2}\right)+k_{2}+q-d_{2}\right)\left[B\left(1+f^{\prime}\left(k_{2}\right)-1\right]=0\right.
\end{aligned}
$$

where ${ }^{c}$ is the (non-negative) Lagrange multiplier associated with (25). The first order condition for the workers (obtained by solving problem (16) with the additional constraint (25)) is: 


$$
-u^{\prime}\left(c_{1}\right)+P u^{\prime}(q)+(1-P) u^{\prime}\left(k_{2}+f\left(k_{2}\right)+q-d_{2}\right)-n^{w}=0
$$

where $n^{W}$ is the (non-negative) Lagrange multiplier associated with (25).

In Appendix 4 it is shown that the type " $c$ " government chooses $d_{2}=\bar{d}$. Moreover, this government is always worse off with capital controls, since the controls impose an additional binding constraint on the capitalists optimum problem. The workers are forced to redistribute differently their consumption over time, but this does not affect the capitalists' welfare in any sense. Hence, the type "c" government would never choose to impose capital controls.

Capital controls have instead both costs and benefits for the government "w". The costs are due to the additional constraint on the workers problem. With capital controls, the workers cannot freely increase their savings to offset the government dissavings. On the other hand, capital controls have the effect of forcing the capitalists to invest more domestically. By applying the implicit function theorem to (26) and (27), it can be shown that $\frac{\partial k_{2}}{\partial q}<0$. Thus, by restricting the access to foreign capital markets, the "w" government obtains the benefit of a larger domestic capital formation, and a larger tax base in period 2.

These considerations provide the basic intuition for the following result, which is formally proved in section 4 of the Appendix:

\section{Proposition 4}

If in the absence of capital controls $b_{2}^{c}>b_{2}^{w}$, then the " $w$ " government always imposes capital controls that are binding on both the workers and the capitalists. The "c" government never imposes capital controls.

The level of the controls imposed by the " $w$ " government is a fraction of the workers' degree of risk aversion. If the $u(\cdot)$ function is very concave, then the workers find it very costly to restrict their means of intertemporal consumption smoothing in exchange for a higher domestic capital stock. In this case even a type "w" would tolerate a substantial amount of capital flight. Conversely, the smaller is the workers' degree of risk aversion, the tighter are the controls imposed by the "w" type (i.e.: the smaller is q). In the extreme case of risk neutrality, the workers' government would always choose $q=0$, thereby completely prohibiting capital outflows. Needless to 
say, this would also happen in the case in which the workers had no access to the international capital markets (i.e., $b_{2}^{w}=0$ ). 12

This finding, namely that left wing governments are more inclined to impose capital controls than right wing governments, is probably consistent with the empirical evidence as suggested by Table 5. As explained at the bottom of this Table, a higher value of the index of capital restriction implies more capital concrols. In Argentina, Chile and Peru the pattern is consistent with the model. A movement towards the right has coincided with a relative relaxation of capital controls. In Mexico and Venezuela there is less volatility in the political orfentation of the government, thus it is harder to identify sharp political changes. The policy of capital controls has also been relatively stable in these countries; for example, Mexico and Venezuela have consistently adopted a policy with relatively few restrictions. In Brazil and the Philippines, center left democratic governments have recently been established following a long period of right-wing dictatorships. It is still early to identify the directions which these two governments will take in terms of capital controls.

\section{Debt Repudiation}

Let us assume now that the government has the option of repudiating the debt in the final period. If the government chooses to repudiate, it suffers a loss, which takes two forms. First of all, the country loses a fraction of its national output, as in Sachs (1985) Cohen-Sachs (1985). 13 This loss of income can be justified as the result of retaliation against the defaulting country, such as trade restriction, seizure of public goods (planes, ships, etc.) or the withdrawal of foreign private investments-- (cf. Aizenman (1987)). Throughout the paper we allow the fraction of income that is lost in the event of a debt repudiation to depend on which government is in office at the time of the repudiation. Specifically, we denote with $\theta^{i}$ the fraction of output lost if the $i$ government repudiates, $i=c, w$, and we assume that $1>{ }_{\theta} C_{\geq \theta}{ }^{W}>0$. This weak inequality is meant to capture the fact that presumably economic and financial exchanges with the rest of the world are more important for the welfare of right wing governments and their constituencies than for socialist governments. Right wing governments may be more likely to rely on foreign investments and foreign trade for the success of their policies than 
TABLE 5

Political Regimes and Capital Controls

$(1967-1986)$

\begin{tabular}{|c|c|c|c|}
\hline & & & Level of \\
\hline & & Political & Capital \\
\hline Country & Time Period & Regime & Restrictions \\
\hline \multirow[t]{4}{*}{ Argentina } & $1967-72$ & right-wing & 0.67 \\
\hline & $1973-75$ & Peronist & 2 \\
\hline & $1976-83$ & military dictatorship & 1.25 \\
\hline & $1984-86$ & center-left & 1 \\
\hline \multirow[t]{3}{*}{ Brazil } & $1967-78$ & right-wing & 1.67 \\
\hline & $1979-84$ & center-right & 2 \\
\hline & $1985 / 86$ & center-left & 2 \\
\hline \multirow[t]{3}{*}{$\underline{\text { Chile }}$} & $1967-70$ & center-left & 2 \\
\hline & $1970-73$ & radical-left & 2 \\
\hline & $1974-86$ & military dictatorship & 1.54 \\
\hline Mexico & $1967-86$ & center-left & 0.34 \\
\hline \multirow[t]{5}{*}{ Peru } & $1967 / 68$ & center-right & 0.5 \\
\hline & $1969-76$ & "left" military & 1.75 \\
\hline & $1977-79$ & "right" military & 1.67 \\
\hline & $1980-84$ & transition to democracy & 1 \\
\hline & $1985 / 86$ & center-left & 2 \\
\hline \multirow[t]{3}{*}{ Philippines } & $1967-72$ & right-wing democratic & 0.5 \\
\hline & $1973-85$ & right-wing dictatorship & 1 \\
\hline & 1986 & center-left democratic ${ }^{\circ}$ & 1 \\
\hline
\end{tabular}




\begin{tabular}{|c|c|c|c|}
\hline & & & Level of \\
\hline & & Political & Capital \\
\hline Country & Time Period & $\underline{\text { Regime }}$ & Restrictions \\
\hline \multirow[t]{5}{*}{ Venezue la } & $1967-69$ & center-left & 0 \\
\hline & $1969-73$ & center-right & 0.2 \\
\hline & $1974-78$ & center-left & 0.6 \\
\hline & $1979-83$ & center-right & 0.8 \\
\hline & $1984-86$ & center-left & 1.67 \\
\hline \multirow[t]{5}{*}{ Uruguay } & $1967-72$ & center-left & 0.83 \\
\hline & $1973-76$ & "right" military & 2 \\
\hline & $1977-81$ & "center" military & 1.2 \\
\hline & $1982-84$ & transition to democracy & 0 \\
\hline & $1985 / 86$ & center-left & 0 \\
\hline
\end{tabular}

Sources: Arthur Banks (ed.). Poilitical Handbook of the World, Binghamton NY 1986.

IMf. Annual Report on Exchange Arrangements and Exchange Restrictions, Washington D.C.., $1967-1986$

Construction of table:

Each IN report 1967-1987 contains a summary table of exchange arrangements and exchange restrictions in all countries of the world. For each year, the countries in this table are assigned 0,1 or 2 points, depending on whether they have no capital restrictions, (0 points), either "separate exchange rates for some or ail capital transactions" or "restrictions on payments for capital transactions" (1 point), or both (2 points). To calculate the restrictiveness of a political regime with respect to capital transactions, these points are summed over and divided by the number of years the regime is in power. Thus, a higher value may be interpreted as characterizing a more restrictive regime. If a regime ends early in a year, this year is counted for the following regime. When uncertain about the attribution of a transition year to two regimes, this year is assigned to both regimes with weights $1 / 2,1 / 2$. 
left wing governments are. As such, the economic costs of the trade disruption that would follow a repudiation are not larger for the w than for the $c$ type. 14 In any case, the qualitative features of the results on repudiation hold also in the case $\theta^{W}=\theta^{C}$.

Secondly, if the country repudiates its external debt, a fraction $1>\phi>0$ of its external assets are seized by foreign creditors. All the parameters of the model including $\phi$ and $\theta^{i}$ are perfectly known to both governments and to the risk neutral lenders.

With a convenient change in notation relative to the previous sections, suppose that if an amount $\gamma_{2}$ is borrowed today by the government, the amount due for repayment next period is $R\left(d_{2}\right) d_{2}, R\left(d_{2}\right)$ being the gross real interest rate. Thus, we allow $R$ to depend on the amount borrowed, $d_{2}$. The value of $d_{2}$ that leaves the government of type $i$ just indifferent between repudiating or repaying the debt is defined by:

$$
\bar{d}^{i}=\left[\theta^{i} f\left(k_{2}\right)+\phi b_{2}^{i}\right] \frac{1}{R\left(\bar{d}^{i}\right)} \quad i=w, c .
$$

If $d_{2}>\bar{d}^{i}$, then the gain of repudiation exceeds its cost, and the government of type $i$ prefers to repudiate. Conversely, if $d_{2}<d^{-i}$ type $i$ prefers to repay the debt.

This formulation of the problem highlights the fact that the costs of debt repudiation are different for the two government types, if either $\theta^{c} \neq \theta^{w}$ or $b_{2}^{w} \neq b_{2}^{c}$. This feature of the model goes well beyond the specific example considered in this paper; it captures the general idea that the cost of repudiation are not uniformly distributed, thus different groups have different preferences regarding this issue. 15

Let us assume for realism and simplicity that for all parameter values:

$$
\mathrm{b}_{2}^{\mathrm{c}}>\mathrm{b}_{2}^{\mathrm{W}}
$$

which simply implies that the non taxable endowment of the capitalists, $e^{c}$, is sufficiently larger than the non taxable endowment of the workers, $e^{w}$.

Under this realistic hypothesis, it is easy to show that in equilibrium the type " $c$ " government never repudiates. In fact, letting $\bar{d}$ denote the maximum amount lent by financial markets, in equilibrium we obtain 
This result can be easily proven by contradiction. ${ }^{16}$

We are left with two cases: a) In the first one, $\bar{d}=\bar{d}>\bar{d}^{-w}$. Here, the " $c$ " type never repudiates; but the " $w$ " type repudiates if in equilibrium $d_{2}>$ $d^{-w}$. Hence, $d^{-w}$ carries the risk free interest rate: $R\left(d^{-w}\right)=1 / 8$. Whereas $d^{-C}$ carries a risk premium: $R\left(d^{-C}\right)=1 / \beta P$. Using (29), this case applies if the following condition holds:

$$
P\left[\theta f\left(k_{2}\right)+\phi b \frac{b_{2}}{C}\right]>\theta^{W} f\left(k_{2}\right)+\phi b_{2}^{W}
$$

b) The second case implies $\bar{d}=\bar{d}^{-w}$ and occurs if (32) is violated. Here in equilibrium neither type repudiates the debt: the government borrows at the risk free rate up to $\bar{d}^{w}$ and cannot borrow at all beyond this point.

The value of $P$ discriminates between the two cases: If $P$ is high (32) holds, if $P$ is low it does not. In particular there exists a value of $P$, say $\bar{p}$, for which if $p>\bar{p}$ case (a) occurs. ${ }^{17}$

In case (b), in which $\bar{d}=\bar{d}^{-w}$, the analys is of the previous sections applies almost identically. Since both governments repay the debt, there is no repudiation risk. Hence, the private sector first order conditions and the optimization problem faced by both government types are identical to those of the previous sections, except in one respect. Namely, here both types take into account that, by increasing $k_{2}$ and $b_{2}^{W}$, they can partially relax their borrowing constraint (since they can shift $d^{-w}$ ). Under a very plausible condition, this aspect does not make any difference. ${ }^{18}$ As in the previous sections, both types always borrow as much as they can, setting $d_{2}=d^{-w}$; see Section 5 of the Appendix for the proof. 19

Case (a), where $\bar{d}=\bar{d}^{-c}>\bar{d}^{-w}$, is more interesting. Now the private sector and both governments must take into account the possibility of debt repudiation. Moreover because of the risk premium, the interest rate faced by the government varies with the size of its external debt: it is $R=1 / \beta$ in the interval $\left[0, d^{-W}\right]$; it jumps to $R=1 / B P$ if $d_{2}>d^{-w}$.

We know from the discussion of case (b) and of the previous sections that neither government type would ever set $d_{2}<d^{-w}$ (see also section 5 of the Appendix). If $d_{2}>d^{-w}$, then the government debt will be repudiated with probability $(1-P)$. Hence the private sector first order conditions 
for $d_{2}>d^{-W}$ are no longer given by (17), and (19). Instead, for the workers they are:

$$
-u^{\prime}\left(c_{1}\right)+P u^{\prime}\left(b_{2}^{w}\right)+(1-P)(1-\phi) u^{\prime}\left(w_{2}+g_{2}^{w}+b_{2}^{w}(1-\phi)\right)=0
$$

and for the capitalists they are:

$$
\begin{aligned}
& -v^{\prime}\left(x_{1}\right)+(1-P)(1-\phi) v^{\prime}\left(b_{2}^{c}(1-\phi)\right)+P v^{\prime}\left(b_{2}^{c}+k_{2}+f\left(k_{2}\right)-w_{2}+g_{2}^{c}\right)=0 \\
& -(1-P)(1-\phi) v^{\prime}\left(b_{2}^{c}(1-\phi)\right)+P v^{\prime}\left(b_{2}^{c}+k_{2}+f\left(k_{2}\right)-w_{2}+g_{2}^{c}\right)\left(8\left(1+f^{\prime}\left(k_{2}\right)\right)-1\right)=0
\end{aligned}
$$

Consider the optimization problem faced by the type " $w$ " government in the interval $\bar{d} \geq d_{2}>\bar{d}^{w}$, subject to these new constraints. Section 5 of the Appendix shows that the solution to this problem yields $d_{2}=\bar{d}$. Thus, the government of type " $w$ " sets either $d_{2}=\bar{d}^{-w}$ or $d_{2}=\bar{d}$. The same result holds for the "c" government (see Appendix). Thus the two governments choose either $\bar{d}^{-W}$ or $\bar{d}$, depending on which one delivers a higher utility for their constituency. In general this comparison is ambiguous.

If in period 1 the government chooses $\bar{d}$, then the debt is repudiated if the "w" government is in office in period 2. The following proposition establishes the conditions under which repudiation is observed.

\section{Proposition 5}

(i) If $d_{2}=d^{-w}$, then no debt repudiation occurs in equilibrium. (ii) If $d_{2}>d^{-w}$, the debt is repudiated if and only if type " $w$ " is in office in period 2. If $w$ is in office in period 1 , then sufficient conditions for case (ii) to occur are (32) and $k_{2}(\bar{d}) \geq k_{2}\left(\bar{d}^{-W}\right)$. If $c$ is in office in period 1 , then case (ii) can occur if, in addition to these two conditions, $\theta^{c}>\theta^{W}$ and $\theta$ is small.

Proof: See Appendix.

This result has several interesting implications. First of all, it shows that the option of repudiating the debt does not eliminate the government incentive to overaccumulate external debt. Secondly, it shows that debt repudiation can occur in equilibrium, if the left wing government unexpectediy holds office in the final period (that is, if $P$ is high enough). This element 
of surprise is needed to induce financial markets to lend beyond the point $d^{-w}$.

\section{Conciusions}

This paper links the political instability of developing countries to their accumulation of pubiic external debt, private capital outflow, income distribution, restrictions on capital outflows and repudiation of external debt. Ali these issues are considered in a simpie dynamic model in which the crucial element is the existence of two social groups behaving noncooperatively. In particular, each group attempts to redistribute income by means of fiscal policy when it holds office. The uncertainty about which group will be in control in the future generates the "political risk" which in turn influences the current economic decisions of private agents and of the government. Thus, this model formalizes the economic effects of political risk, and, for instance, it is consistent with the observation that capital flight are more likely to occur in politically turbulent periods.

We have chosen to present the simplest possible version of the models, to enhance readibility. However, the qualitative results of the anaiysis are robust to generalizations of the model in several directions. For instance, the basic results generalize to an infinte horizon model (at least for some functional forms of the utility functions); to a model with an endogenous iabor supply; to a model in which the workers are prevented to hold external assets; to a model in which the government provides also public goods; with certain caveats (described in more detail in Alesina-Tabellini (1987)) to a model in which the preferences of the two governments are less extreme; to a model in which the probability of the change of government is endogenously derived by the underlying preferences of rational voters (see, again, Aiesina - Tabellini (1987) and Alesina (1988a)); to a model in which there exist upper bounds on tax rates so that the governments cannot completely expropriate their adversaries.

Several additional issues for a politico-economic explanation of the external debt of developing countries which deserve attention have not been considered. For instance, we have focused only on one kind of social conflict, between owners of physical capital and owners of human capital. An additional important social conflict is the one between the tradeable versus nontradeable goods sectors, which in several circumstances may imply a 
conflict between industry and agriculture or certain industrial sectors and others. Workers and capitalists in, say, the tradeable sector may have economic interests in conflict with those of workers and capitalists in the nontradeable sector. For example, the two groups may disagree about the desirability of exchange rate devaluation, trade restrictions and repudiation of external debt.

Second, we have not explicitly included monetary variables in our model, thus we have not addressed important issues such as inflation and devaluation. Rapid changes in the price level can have important redistributive consequences which affect and are affected by political factors. In particular, these monetary phenomena may contribute in an important way to explain capital flight (Dornbusch (1985), Cuddington (1985)).

Third, politico economic considerations crucially affect the choice between "repudiation" and "solvency with adjustment". In general different social groups gain and lose depending upon which policy option is adopted. 


\section{Footnotes}

1. Sachs (1984) describes this phenomen as "a special sort of intermediation: the private sectors of Latin America made offshore dollar loans to the Latin American public sectors". With specific reference to Argentina, Dornbusch and de Pablo (1987) write that "commercial banks in New York, Zurich and Tokyo had lent to the government the resources to finance capital flight which returned to the same banks as deposits."

2. For a detailed discussion of alternative measures of capital flight, see Cumby-Levich (1987). They show that different definitions of capital flight and different data sources imply some significant differences in the estimates. However, there is no doubt about the order of magnitude of capital flights: in several countries and several time periods they have been a substantial fraction of external borrowing.

3. See, for instance, Dornbusch-Fischer (1986).

4. Political polarization and instability in Latin America is a fairly self evident and well documented fact. Mallon and Sourroville (1975) as quoted by Dornbusch and de Pablo (1987) capture this point and write that "Decision Makers in Argentina have quite consistently attempted to adopt policy positions that seemed designed to tear society apart rather than to forge new coalitions." Dornbusch and de Pablo (1987) emphasize that this political polarization "has meant that much of national wealth is held abroad and taxes are paid by only a few."

5. See, for instance, Kaufman (1986), Haggard (1986) and the references quoted therein. In addition to the political conflict amongst different factor of production, that is the focus of this paper, many of the countries under examination also have a conflict across sectors of the economy (such as agricultural, industrial and commercial). See for instance Sachs (1985) and Frieden (1987). Incorporating this richer political dimension in the analysis of this paper is a difficult task, which is left for future research.

6. Related findings are obtained by Alesina-Tabellini (1987) TabelliniAlesina (1988) and Persson-Svensson (1987) for domestic government debt, in a closed and open economy respectively.

7. This is a highly simplified treatment of repudiation risk, since repudiation costs are given exogenously and not endogenously derived from 
lender's behavior. For a severe criticism of these models see Gersovitz (1985); for a different treatment of external debt repudiation see Grossman-Van Huyck (1986), Bulow-Rogoff (1987) and (1988).

8. The result that left wing governments are more likely to repudiate the debt is also consistent with the view that the burden of debt repayment falls disproportionately on labor income (as opposed to capital income), as emphasized by Dornbusch (1986). It is also consistent with the observation that the Soviet Union, China and Cuba repudiated their external debts after their revolutions. Alesina (1988b) discusses related issues for the case of the internal debts of several European countries in the interwar period.

9. "Workers" are prevented from acquiring domestic capital in order to emphasize the difference between the two groups. Alternatively one might capture a difference between "rich" and "poor" due to different endowment rather than by their productive role. This alternative specification has not been explored yet.

10. An alternative specification which leads to qualitatively analogous result would be to have transfers proportional to wages and capital rather than lump sum. This would imply to let $\tau_{i} \leq 0, z_{i} \geq 0$ and set $g_{i}^{w}=0$ and $g_{i}^{C}$ $=0$.

11. In particular, the qualitative results of the model survive the imposition of either of these two additional constraints on workers' behavior: a) $b_{2}^{w}=0$; b) $b_{2}^{w} \geq 0$. Case (a) implies that the workers have no access to international financial markets. Under this assumption a 11 the results of this model are strengthened. (The proof is available from the authors). Case (b), which implies that workers cannot borrow abroad, can be easily accounted for. In fact, we show below that in equilibrium we obtain $b_{2}^{W}>0$. Thus, the constraint given in (b) is never binding.

12. These results about capital controls should be slightly qualified if the labor supply were elastic. In this case the imposition of capital controls on the workers would in general affect both their intertemporal allocation of consumption and leisure. By working through the proof of Proposition 4 it is easy to verify that the result about the workers' government does not change. For the "c" government the elasticity of leisure with respect to capital controls may reinforce or weaken the aversion to capital controls depending on the utility function of workers 
(i.e. if capital controls make them work more or less).

13. As in Sachs (1985) and Cohen-Sachs (1985) we assume that the severity of the "punishment", i.e. he fraction of output lost in case of repudiation, is independent of the amount of repudiation. This feature of the model eliminates partial repudiation as a rational choice. For a more general version of a related model of repudiation in which the extent of the punishment is a function of the amount of debt repudiated see calvo (1987).

14. The case $\theta^{W}>{ }_{\theta}^{C}$ is less plausible and, in addition, it has the same similar qualitative implications of the case considered in the text as long as $b_{2}^{c}$ is sufficiently bigger than $b_{2}^{w}$.

15. In general there are other reasons, besides those considered in the paper, for arguing that the costs of debt repudiation affect differently different groups of the population. For instance, the traded goods and financial sectors are more likely to be harmed than the non-traded goods sectors. Diaz-Alejandro (1984) contains some discussion of these issues.

16. Suppose that (31) were violated: then it must be that $\bar{d}^{w} \geq \bar{d}>\bar{d}^{C}$. . Thus, $d^{-c}$ carries the risk free interest rate, $R\left(d^{-c}\right)=1 / s$, whereas $d^{-w}$ carries a risk premium. If type "c" is in office in period 2 (which happens with probability $P$ ) and $d_{2}=d_{-}^{-w}$, then the debt will be repudiated. Hence, $R\left(\bar{d}^{-w}\right)=1 /[B(1-P)]>R\left(d^{-c}\right)$. Inserting these expressions for $R\left(d^{-w}\right)$ and $R\left(d^{-C}\right)$ in (29) and using (30) yields a contradiction.

17. Define $P \star$ such as the value for which (32) holds as an equality; namely $P *$ satisfies

$$
P^{*}=\frac{\theta^{w} f\left(U_{2}\left(P^{*}\right)\right)+\phi b_{2}^{w}\left(P^{*}\right)}{{ }_{\theta} c_{f}\left(u_{2}\left(P^{*}\right)\right)+\theta b_{2}^{C}\left(P^{*}\right)}
$$

It can be easily shown that $1>p *>0$. However $p *$ may not be unique. Define $\bar{p}$ as the highest value of $p *$ and $\underline{p}$ as the lowest. Then case (a) occurs for $p>\bar{p}$ and case $(b)$ for $p<\underline{p}$. For $\bar{p}>p>p$ either case can occur depending

18. The condition is that $\theta f^{\prime}\left(k_{2}\right) \frac{\partial k_{2}}{\partial g_{1}^{c}}<1$. If this conditions is relaxed, it would no longer be true that the type " $w$ " sets $g_{1}^{c}=0$. The results concerning government debt are independent of whether or not this conditions holds. 
19. Note that here, unlike in Section 3 , the size of the debt constraint $\vec{d}^{w}$ depends on which government is in office in the first period (via the terms $k_{2}$ and $b_{2}^{w}$ ). 


\section{REFERENCES}

Aizenman, Joshua (1987), "Investment, Openness and Country Risk", IMF working paper, WP/87.

Alesina, Alberto (1988a), "Credibility and Policy Convergence in a Two-Party System with Rational Voters," American Economic Review, forthcoming.

(1988b), "The End of Large Public Debt," in Surviving with a High Public Debt, Cambridge University Press, forthcoming.

and Guido Tabellini (1987), "A Positive Theory of Fiscal Deficits and Government Debt in a Democracy," NBER Working Paper No. 2308 (August).

Ascher, William (1984), "Scheming for the Poor: The Politics of Redistribution in Latin America," Cambridge: Harvard University Press.

Banks, Arthus (ed.), Political Handbook of the Wor Id, 1986.

Bulow, Jeremy and Kenneth Rogoff (1987), "A Recontracting Model of Externa Debt", Working Paper, Hoover Institution.

and (1988), "Soverign Debt: Is to Forgive to Forget?", mimeo.

Calvo, Gultiermo (1987): "Debt Repudiation: The Role of Expectations", unpublished.

Cohen, Daniel and Jeffrey Sachs (1985), "LDC Borrowing with Default Risk", Kredit and Kapital (special issue on international banking).

Cuddington, John (1986), "Capital Flight: Issues, Estimates and Explanations," Princeton Essays in International Finance, 58 ([0.ember).

Cumby, Robert and Richard Levich (1987), "On the Definition and Magnitude of Recent Capital Flight," N8ER Working Paper No. 2275 (June). 
Diaz-Alejandro Carlos (1987): "Latin American Debt: I Don't Think We Are in Kansas Anymore" Brookings Papers on Economic Activity, 2: 335-389.

Dooley, Michael, William Helkie, Ralph Tyron and John Underwood (1983), "An Analysis of the External Debt Position of Eight developing Countries Through 1930," Journal of Development Economics, 22, 283-318.

Dornbusch, Rudiger (1985), "External debt, Budget Deficits and Disequilibrium Exchange Rates," in Gordon Smith and John Cuddington (eds.), International Debt and the Developing Countries, Washington, D.C.: World Bank.

(1986) "Dollars, Debt and Deficits" MIT Press, Cambridge, MA.

(1987) "Debt Problems and the World Macro Economy" NBER Working Paper No. 2379 (September).

and Jouan Carlos de Pablo (1987): "Argentine Debt and Macroeconomic Instability" NBER Working Paper No. 2378 (September). and Stanley Fischer (1986) "Third World Debt", Science, 234.

Eaton, Jonathon and Mark Gersovitz (1987), "Country Risk and the Organization of International Capital Transfers," NBER Working Paper No. 2204 (Apri]).

(1987), "Public Debt guarantees and Private Capital Flights," Wor Id Bank Economic Review, 1, 377-95.

Fischer, Stanley (1980): "Dynamic Inconsistency, Cooperation and the Benevolent Dissembling Government", Journal of Economics, Dynamics and Control, February.

Frieden, Jeff (1987), "Winners and Losers in the Latin American Debt Crisis", paper presented at the September 1987 meetings of the APSA.

Grossman, Herschel and John Van Huick(1987): "Sovereign Debt as a Contingent Claim: Excusable Default, Repudiation and Reputation, NBER, Working Paper 
no. 1673 .

Giovannini, Alberto (1988), "Capital Controls and Public Finance: The Case of Italy" in Surviving with a High Public Debt, Cambridge University Press, forthcoming.

Haggard, Stephen (1986), "The Politics of Adjustment: Lessons from the IMF's Extended Fund Facilities," in Miles Kahler (ed.), The Politics of International Debt, Ithaca, NY: Corne 11 University Press.

Internationa 1 Monetary Fund, "Annual Reports on Exchange Arrangements and Exchange Restrictions," (various issues).

Ize, Alain and Guillermo Ortiz (1987), "Fiscal Rigidities, Public Debt and Capital Flight," IMF Staff Papers (June), 311-32.

Kaufman, Robert (1986), "Democratic and Authoritarian Responses to the Debt Issue: Argentina, Brazil and Mexico," in Miles Kahter (ed.), The Politics of International Debt, Ithaca, NY: Cornell University Press.

Khan, Moshin and Naderi UT Haque (1986), "Foreign Borrowing and Capital Flight: A Formal Analysis," IMF Staff Papers, 32, 606-28.

Persson, Torsten and Lars Svensson (1987), "Checks and balances on the Government Budget," University of Rochester Working Paper.

Sachs, Jeffery (1985), "Theoretical Issues in International Borrowing," Princeton Studies in Internationa 1 Economics.

Tabellini, Guido and Alberto Alesina (1988), "Does the Median Voter Like Budget Deficits?", unpublished. 


\section{APPENDIX}

\section{Derivation of Equation (22)}

The type " $c$ " government optimization problem in period 1 can be written as follows: maximize (20) subject to (13) in the text and to the following first order conditions of the private sector derived in the text as equations (17), (19a) and (19b) respectively.

$F\left(b_{2}^{W}, k_{2}, d_{2}\right) \equiv-u^{\prime}\left(e^{W}-g b_{2}^{W}\right)+P u^{\prime}\left(b_{2}^{W}\right)+(1-P) u^{\prime}\left(k_{2}+f\left(k_{2}\right)+b_{2}^{W}-d_{2}\right)=0$

$H\left(b_{2}^{c}, k_{2}, d_{2}\right) \equiv-v^{\prime}\left(f\left(k_{1}\right)+k_{1}+e^{C}-\beta b_{2}^{C}-k_{2}+\beta d_{2}\right)+$

$$
(1-P) v^{\prime}\left(b_{2}^{c}\right)+P v^{\prime}\left(b \frac{c_{2}}{+k_{2}}+f\left(k_{2}\right)-d_{2}\right)=0
$$

$G\left(b_{2}^{c}, k_{2}, d_{2}\right) \equiv-(1-P) v^{\prime}\left(b_{2}^{c}\right)+P v^{\prime}\left(b \frac{c}{2}+k_{2}+f\left(k_{2}\right)-d_{2}\right) \cdot\left[B\left(1+f^{\prime}\left(k_{2}\right)\right)-1\right]=0$

The government budget constraint has been substituted in (A.1) - (A.3). The government maximizes with respect to $k_{2}, b_{2}^{C}, b_{2}^{W}, d_{2}$. Let $\zeta$, $i$ and $u$ denote the Lagrange multipliers associated with the constraints (A.1), (A.2) and (A.3) respectively. Moreover, let $F_{i}, G_{j}$ and $H_{j}$ denote the derivatives of $F, G$ and $H$ with respect to the variable $i$. Then, the first order conditions of this optimization problem can be written, after rearrangements as:

$$
\begin{aligned}
& { }_{b_{2}^{c}}+{ }^{\prime} G_{b_{2}^{c}}=0 \\
& { }_{b} F_{b_{2}^{W}}=0 \\
& \lambda H_{k_{2}}+\mu G_{k_{2}}+\zeta F_{b_{2}^{W}}^{W}=0 \\
& \beta V^{\prime}\left(f\left(k_{1}\right)+k_{1}+e^{c}-\beta b_{2}^{c}-k_{2}+\beta d_{2}\right)- \\
& -\beta P v^{\prime}\left(f\left(k_{2}\right)+k_{2}+b_{2}^{c}-d_{2}\right)+\lambda H_{d_{2}}+\mu G_{d_{2}}+\zeta F_{d_{2}}-\gamma=0
\end{aligned}
$$




$$
r\left(\bar{d}-d_{2}\right)=0
$$

Since $F_{b_{2}^{W}}=0,(A .5)$ implies $\zeta=0$. Since $\underset{b_{2}^{c}}{H}, G_{b_{2}^{C}}, H_{k_{2}}, G_{k_{2}}=0,(A .4)$ and (A.6) imply $\lambda=\mu=0$. As a result, (A.7) impiies equation (22) in the text.

\section{Proof of Proposition 2}

By following the same steps as in Section 1 of this Appendix, the problem of the type " $w$ " government in period 1 can be written as:

$$
d_{2}, b_{2}^{w}, k_{2}, b_{2}^{c a x}\left\{u\left(y_{1}+k_{1}+e^{w}+\beta d_{2}-\beta b_{2}^{w}\right)+\beta\left\{P u\left(b_{2}^{w}\right)+(1-P) u\left(k_{2}+f\left(k_{2}\right)+b_{2}^{w}-d_{2}\right)\right\}\right\}
$$

Subject to (13) in the text and to:

$$
\begin{aligned}
& \hat{F}\left(b_{2}^{w}, k_{2}, d_{2}\right) \equiv-u^{\prime}\left(k_{1}+e^{w}+f\left(k_{1}\right)+B d_{2}-3 b_{2}^{w}\right)+P u^{\prime}\left(b_{2}^{w}\right)+(1-P) u^{\prime}\left(k_{2}+f\left(k_{2}\right)+b_{2}^{w}-d_{2}\right)=0 \\
& \hat{H}\left(b_{2}^{c}, k_{2}, d_{2}\right) \equiv-v^{\prime}\left(e^{c}-\beta b_{2}^{c}-k_{2}\right)+(1-P) v^{\prime}\left(b_{2}^{c}\right)+P v^{\prime}\left(b_{2}^{c}+k_{2}+f\left(k_{2}\right)-d_{2}\right)=0
\end{aligned}
$$

and to (A.3). Note that the functions $\hat{F}(\cdot)$ and $\hat{H}(\cdot)$ are identical to $F(\cdot)$ and $H(\cdot)$ in Section 1 of the appendix in all respects except for the terms referring to $c_{1}$ and $x_{1}$. This is because $c_{1}$ and $x_{1}$ are dffferent depending upon which government is in office in period 1 . Denoting by $\hat{\zeta}, \hat{\lambda}$ and $\hat{\mu}$ the Lagrange multipliers assocfated with (A.10), (A.11) and (A.3) respectively, we can write the first order conditions of this problem as:

$$
\begin{aligned}
& \hat{\zeta} \hat{F}_{b_{2}^{w}}=0 \\
& \hat{\lambda}_{b_{2}^{c}}+\hat{\mu}_{b_{2}^{c}}=0 \\
& B(1-P) u^{\prime}\left(k_{2}+f\left(k_{2}\right)+b_{2}^{w}\right)+\hat{\lambda} \hat{H}_{k_{2}}+\hat{\mu} G_{k_{2}}+\hat{c} \hat{F}_{k_{2}}=0
\end{aligned}
$$




$$
\begin{aligned}
\text { su ' }\left(k_{1}+f\left(k_{1}+e^{W}+B d_{2}-s b_{2}^{W}\right)\right. & -\beta(1-P) u^{\prime}\left(k_{2}+f\left(k_{2}\right)+b_{2}^{w}-d_{2}\right) \\
+ & \hat{\lambda} \hat{H}_{d_{2}}+\hat{j} G_{d_{2}}+\hat{z} \hat{F}_{d_{2}}-\hat{\gamma}=0
\end{aligned}
$$

$\hat{Y}\left(\vec{d}-d_{2}\right)=0$

Since $\hat{F}_{W} \neq 0, \quad(A .12)$ implies $\hat{\zeta}=0$. By computing the partial derivatives . $\quad b_{2}^{W}$

of $H(\cdot), G(\cdot)$ and $R(\cdot)$ and rearranging, we obtain:

$$
\hat{r}=B P u^{\prime}\left(b_{2}^{W}\right)+B(1-P) u^{\prime}\left(k_{2}+f\left(k_{2}\right)+b_{2}^{W}-d_{2}\right)\left(1+f^{\prime}\left(k_{2}\right)\right) A
$$

where

$$
A \equiv \frac{b_{2} c_{2} \hat{H}_{2}-\hat{H}_{b} c_{2}{ }^{G} d_{2}}{G_{k_{2}} \hat{H}_{2} b_{2}-\hat{H}_{k_{2}} G_{2} b_{2}^{c}}
$$

Some tedious algebra establishes that $A>0$ Hence, (A.16), (A.17) imply that $d_{2}=$ $\bar{d}$. The rest of the proof of Porposition 2 is contained in Section 2 of the text.

\section{Proof of Proposition 3}

Consider the system of equations given by the capitalists first order conditions when the government of type $c$ is in office, equations $(A .2)$ and (A.3). Applying the implicit function theorem at the point $d_{2}=a$ we obtain

$$
\begin{gathered}
{\left[\begin{array}{c}
\frac{\partial k_{2}}{\partial d_{2}} \\
\frac{\partial b_{2}^{c}}{\partial d_{2}}
\end{array}\right]=-\left[\begin{array}{cc}
G_{k_{2}} & b_{2}^{c} \\
H_{k_{2}} & H_{b_{2}^{c}}
\end{array}\right]^{-1}\left[\begin{array}{l}
G_{d_{2}} \\
H_{d_{2}}
\end{array}\right]=} \\
=\left[\begin{array}{cc}
H_{2}^{c} & -b_{2}^{c} \\
-H_{k_{2}} & G_{k_{2}}
\end{array}\right]\left[\begin{array}{l}
G_{d_{2}} \\
H_{d_{2}}
\end{array}\right] \frac{1}{\Delta}
\end{gathered}
$$


where $\Delta=G_{k_{2}} H_{b_{2}}{ }^{-}{ }_{b_{2}}{ }^{H_{k}}$. By the second order sufficient conditions for the private sector optimization problem, $\Delta>0$. We thus have:

$$
\begin{aligned}
& \frac{\partial k_{2}}{\partial d_{2}}=-\frac{1}{\Delta}\left[{ }_{b}{ }_{2}{ }_{2}^{G} d_{2}-G_{b_{2}} c^{H} d_{2}\right] \\
& \frac{\partial b_{2}^{c}}{\partial d_{2}}=-\frac{1}{\Delta}\left[-H_{k_{2}} G_{d_{2}}+G_{k_{2}} H_{d_{2}}\right]
\end{aligned}
$$

Computing the expression for the partial derivatives of $H(\cdot)$ and $G(\cdot)$ from (A.2) and (A.3), it can be shown that the right hand sides of (A.19) and (A.20) are both positive. By repeating the same procedure, from (A.2) and (A.3) we also obtain that:

$$
\begin{aligned}
& \frac{\partial k_{2}}{\partial P}=-\frac{1}{\Delta}\left\{{ }_{b_{2}^{c}} G_{p}-G_{b_{2}^{c}} H_{p}\right\}>0 \\
& \frac{\partial b_{2}^{c}}{\partial P}=-\frac{1}{\Delta}\left[-H_{k_{2}} G_{p}+G_{k_{2}} H_{p}\right\}<0
\end{aligned}
$$

Consider now the workers' first order condition when the government in period 1 is of type " $c$ ", equation (A.1). By the implicit function theorem at the point $d_{2}=\bar{d}$ we obtain:

$$
\begin{aligned}
& \frac{\partial b_{2}^{W}}{\partial d_{2}}=\frac{F_{d_{2}}}{F}>0 \\
& b_{2}^{W} \\
& \frac{\partial b_{2}^{W}}{\partial P}=-\frac{F_{p}}{F}>0
\end{aligned}
$$

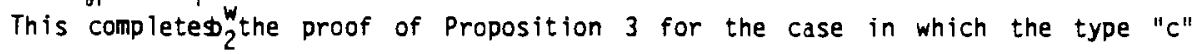
government is in office in the first period. In order to prove Proposition 3 for the case in which the type " $w$ " is in office in period 1, simply repeat these 
procedures, replacing equations (A.1) and (A.2) by equations (A.10) and (A.11) respectively.

\section{Proof of Porposition 4}

The proof of the statement concerning the " $c$ " government is immediate. Here we prove the statement concerning the " $w$ " government. Suppose that the capital controls are binding for both groups, i.e., $q=b_{2}^{C}=b^{W}$ and $\pi^{c}, r^{W}>0$.

The problem of the " $w$ " type can be written as follows:

$$
\operatorname{Max} u\left(y_{1}+k_{1}+e_{1}-\beta q+B d_{2}\right)+\beta\left[P u(q)+(1-P) u\left(k_{2}+f\left(k_{2}\right)+q-d_{2}\right)\right]
$$

subject to (26), (27), (28) and (13).

Let us indicate with $\bar{H}, \bar{G}$ and $\bar{R}$ the constraints (26), (27), and (28) respectively, and let $\bar{\lambda}, \bar{\mu}$ and $\bar{\zeta}$ be the multipliers associated with these constraints. $\bar{y}$ is the Lagrange multiplier of (13).

The first order conditions of this problem impiy:

$$
\bar{r}=B P u^{\prime}(q)+B(1-P)\left[\left(1+f^{\prime}\left(k_{2}\right)\right] u^{\prime}\left(k_{2}+f\left(k_{2}\right)+q-d_{2}\right) B-\eta^{w}\right.
$$

where $B \equiv-\frac{\bar{H}_{d_{2}}+\bar{G}_{d_{2}}}{\bar{H}_{k_{2}}+\bar{G}_{k_{2}}}>0$.

(A.22) is the analogue of (A.17) for this modified problem. Note that since $\pi^{W}>0$ because the capital controls are binding, $\bar{y}$ is not necessarily positive. Thus, if the capital controls are binding $d_{2}$ is not necessarily equal to $\bar{d}$.

Let $z(q)$ be the indirect utility function associated to this problem. By the envelope theorem it follows that

$$
\frac{\partial z(g)}{\partial q}=\frac{\partial L}{\partial q}
$$

where $L$ is the Lagrangian associated to problem (A.21). After rearrangements it follows that:

$$
\frac{\partial L}{\partial q}=\beta \eta^{w}+\beta \bar{\lambda}\left[v^{\prime \prime}\left(e^{c}-k_{2}-q\right)+P v^{\prime \prime}\left(f\left(k_{2}\right)+k_{2}+q-d_{2}\right)\left(1+f^{\prime}\left(k_{2}\right)\right)\right]
$$


The first term on the right hand side of (A.24) is positive, the second is negative (since $\bar{\lambda}>0$ ). Consider equation (A.24) at the point in which $q$ is just binding for the workers and strictly binding for the capitalists. Thus, if $q^{\star}$ is this point it follows that $q^{*}=b_{2}^{W}<b_{2}^{C}$, where $b_{2}^{W}$ and $b_{2}^{c}$ are the external assets that would be chosen without capital controls. (A.24) implies that

$$
\frac{\partial L}{\partial q}<0 \quad \text { for } b_{2}^{C}>q \geq q^{*}
$$

(A.25) follows from the fact that $3 \eta^{W}=0$ for $q \geq q^{*}$ while the second term remains negative for $q<b_{2}^{c}$ (i.e., if the capital controls are binding for the capitalist). If $a \geq b_{2}^{c}$ capital controls are not binding for anyone so they do not affect anybody's welfare. Since the function $z(q)$ is continuous, it follows that it has a maximum for $q<q^{*}$, that is for a value of $q$ such that the controls are binding on both the capitalists and the workers.

More generally, it follows from (28) in the text that, for a given $q, \eta^{c}$ is smaller the smaller is the concavity of $u(\cdot)$. Hence, the optimal value of $q$ for the " $w$ " type (i.e., the value of q such that the right hand side of (A.24) is zero) tends in general to be smaller the less concave is $u(\cdot)$. That is, as claimed in the text, the controls imposed by the " $w$ " type are stricter the smaller is the concavity of $u$. In the limit, if workers are risk neutral, then (28) implies that $n^{W}=0$. According to (A.24), if then follows that $\operatorname{argmax} z(q)=0$.

\section{Proof of Proposition 5}

Consider the governments optimization problem for case (b), in which $\bar{d}=\bar{d}^{w}$. The problem is identical to those of sections 1 and 2 of the appendix, except that now $\bar{d}=\left[\theta f\left(k_{2}\right)+\Phi b_{2}^{w}\right]$ B. Hence the government first order conditions with respect to $k_{2}$ and $b_{2}^{w}$ now take into account the effect of $k_{2}$ and $b_{2}^{w}$ on $\bar{d}$. Moreover, since government debt here is treated as a loan rather than as a discount bond, the government now chooses $D_{2}=R d_{2}=\frac{1}{B} d_{2}$. With these changes, the first order conditions of type " $c$ " are given by (A.6), (A.7) (with $d_{2}$ replaced by $\mathrm{O}_{2}$ in them), by (A.8) and by:

$$
\begin{aligned}
& { }_{b_{2}} \mathrm{~b}_{2}^{w}+r=0 \\
& \lambda H_{k_{2}}+{ }^{w} G_{k_{2}}+{ }_{\zeta} F_{k_{2}}+{ }_{r \theta} C_{f^{\prime}}\left(k_{2}\right)=0
\end{aligned}
$$


To prove that the solution is at $d_{2}=\bar{d}$, proceed by contradiction. suppose that $d_{2}<d$. Then $Y=0$ by (A.8) and $\zeta=0$ by (A.5)'. But then $(A .4)$ and (A.6)' imply $\lambda=\mu=0$, so that (A.7) implies $Y>0$ (cf. (22)), a contradiction. Hence the first order conditions must be satisfied at $d_{2}=\bar{d}$. Repeating exactly the same procedure for the type " $w$ " government yields that this type sets $d_{2}=d^{w}$. This completes the proof for case (b) of the text, where $\bar{d}=\bar{d}^{w}$. Moreover, it also proves that, in case (a), where $\bar{d}=\bar{d}^{c}>\bar{d}^{w}$, neither type would ever set $d_{2}<\vec{d}^{w}$. Now consider case (a) in the interval $\vec{d}^{c} \geq d_{2}>d^{w}$, and proceed as in sections 2 and 1 of the Appendix. Suppose that type " $w$ " is in office in period 1. His expected utility function over this range is:

$$
u\left(k_{1}+f\left(k_{1}\right)+e^{W}-B b_{2}^{W}+B P D_{2}\right)+B P u\left(b_{2}^{W}\right)++B(1-P) u\left(k_{2}+f\left(k_{2}\right)\left(1-\theta^{W}\right)+b_{2}^{W}(1-\phi)\right)
$$

where we used the condition $D_{2}=d_{2} / 8 P$. The constraints are given by (33) (35) that are rewritten here as:

$$
\begin{aligned}
& \bar{F}\left(b_{2}^{W}, k_{2}, D_{2}\right)=-u^{\prime}\left(k_{1}+e^{W}+f\left(k_{1}\right)+\beta_{\left.B P D_{2}-\beta b_{2}^{w}\right)+}^{W}\right. \\
& +P u^{\prime}\left(b_{2}^{w}\right)+(1-P)(1-\phi) u^{\prime}\left(k_{2}+f\left(k_{2}\right)\left(1-\theta^{W}\right)+b_{2}^{w}(1-\phi)\right)=0 \\
& \bar{H}\left(b_{2}^{c}, k_{2}, D_{2}\right) \equiv-v^{\prime}\left(e^{c}-\beta b_{2}^{c}-k_{2}\right)+ \\
& +(1-P)(1-\phi) v^{\prime}\left(b_{2}^{c}(1-\phi)+P v^{\prime}\left(b_{2}^{c}+k_{2}+f\left(k_{2}\right)-D_{2}\right)=0\right. \\
& \bar{G}\left(b_{2}^{c}, k_{2}, D_{2}\right) \equiv-(1-P)(1-\phi) v^{\prime}\left(b_{2}^{c}(1-\phi)\right)+ \\
& +P v^{\prime}\left(b_{2}^{c}+k_{2}+f\left(k_{2}\right)-D_{2}\right)\left[B\left(1+f^{\prime}\left(k_{2}\right)\right)-1\right]=0
\end{aligned}
$$

and by the borrowing constraint: 


$$
\left[\theta^{w} f\left(k_{2}\right)+\phi b{ }_{2}^{c}\right] \geq D_{2}
$$

Adopting the same notational conventions of sections 1 and 2 of the Appendix, we can write the first order conditions of this optimization problem as:

$$
\begin{aligned}
& \bar{\zeta} \bar{F}_{b_{2}^{w}}^{w}=0
\end{aligned}
$$

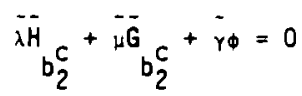

$$
\begin{aligned}
& B(1-P) u^{\prime}\left(k_{2}+f\left(k_{2}\right)+b_{2}^{W}\right)\left(1+f^{\prime}\left(k_{2}\right)\right)+\bar{\lambda} \bar{H}_{k_{2}}+j \tilde{G}_{k_{2}}+\overline{\zeta F_{k_{2}}}+ \\
& +\dot{r} \theta^{w} f^{\prime}\left(k_{2}\right)=0 \\
& B P U^{\prime}\left(k_{1}+f\left(k_{1}\right)+e^{W}+B P D_{2}-B b_{2}^{W}\right)+\ddot{\lambda} \tilde{H}_{D_{2}}+\ddot{j} \tilde{G}_{D_{2}}+\tilde{\zeta} \tilde{F}_{D_{2}}-\dot{\gamma}=0 \\
& \dot{\gamma}\left[\theta f\left(k_{2}\right)+\phi b_{2}^{c}-D_{2}\right]=0
\end{aligned}
$$

From $(A .12)^{\prime}, \bar{\zeta}=0$. Now proceed by contradiction. Suppose that $\bar{\gamma}=0$. Inserting (A.13)' and (A.14)' in (A.15)' we obtain:

$$
P u^{\prime}\left(c_{1}\right)+(1-P) U^{\prime}\left(c_{2}\right)\left(1+f^{\prime}\left(k_{2}\right)\right) \dot{A}=0
$$

where

$$
\tilde{A}=\frac{{ }_{b} c}{\bar{H}_{D_{2}}-\tilde{G}_{D_{2}} \tilde{H}_{b}^{c}}
$$

Some tedious algebra establishes that $\bar{A}>0$. Hence we obtain a contradiction, and $\dot{\gamma}>0$. By (A.16)' it then follows that $D_{2}=\bar{d}^{C} / B P$, or that $d_{2}=\bar{d}^{c}=\bar{d}$. Repeating exactly the same procedure for the type " $c$ " government, we obtain that in the interval $\bar{d}^{c} \geq d_{2}>d^{w}$. type " $c$ " also goes to the corner, by setting $d_{2}=J^{c}$. Thus, both types either set $d_{2}=\bar{d}^{*}$ or $d_{2}=\bar{d}$. 
In order to see whether $\bar{d}^{w}$ or $\bar{d}$ yields a higher expected utility for the two types, we need to compare the value of the capital shock at $\bar{d}, k_{2}(\bar{d})$, and at $\vec{d}^{w}, k_{2}\left(\vec{d}^{w}\right)$. In genera1, this comparison is ambiguous. The external assets of the capitalist have a lower expected return at the point $\bar{d}$ than at $\bar{d}^{w}$, since a fraction $\phi$ of them would be seized in the event of a debt repudiation. However, the marginal utility of income for the capitalists is higher in that case. In other words, the income and substitution effects go in opposite direction, and $b_{2}^{c}$ can be either higher or lower at $d$ than at $\vec{d}^{w}$. On the other hand, it can be shown that the capitalists always have more at $\bar{d}$ than at $\bar{d}^{\mathrm{w}}$ (because of a "Ricardian equivalence" argument in the event that type " $c$ " holds office next period). For this reason, the case in which $k_{2}(\bar{d}) \geq k_{2}\left(\bar{d}^{w}\right)$ seems more plausible. In this case, the type " $w$ " government always goes at $\bar{d}$ rather than at $\bar{d}^{w}$. Consider for simplicity the case $k_{2}(\bar{d})=k_{2}\left(\bar{d}^{w}\right)$. If the " $w^{\prime \prime}$ type borrows up to $\bar{d}$, it can effect a larger transfer to its constituency than if it borrowed up to $\bar{d}^{w}$. Suppose that this extra amount of transfers $\left(\bar{d}-\bar{d}^{w},\right)$ is spent by the workers in period 1: their utility in period 1 is higher. Moreover, their expected utility in the second period is the same as if the government had borrowed only up to $\vec{d}^{w}$ (since, by definition of $\vec{d}^{w}$, type $w$ is just indifferent between repudiating the debt or repaying $\vec{d}^{w}$ ). If the workers spread the extra transfers optimally across time, their overall utility is even higher. Thus, if $k_{2}(\bar{d})=k_{2}\left(\bar{d}^{w}\right)$ type " $w$ " is better off at $\bar{d}$ than at $\bar{d}^{w}$. A fortiori, this is also true if $k_{2}(\bar{d})>k_{2}\left(\bar{d}^{w}\right)$. Sumarizing, if $k_{2}(\bar{d}) \geq k_{2}\left(\bar{d}^{w}\right)$, then type " $w^{\prime \prime}$ always sets $d_{2}=\bar{d}$.

Consider now type "c". Suppose, for simplicity, that $\phi=0$ but ${ }_{\theta} c>\theta^{W}$. It is easy to show that if $P$ is sufficiently high, then $d_{2}=\bar{d}$. Intuitively, if $\phi=0$, the cost of debt repudiation is only born by the government who repudiates. As a consequence, the results of the previous section apply: type $c$ does not fulty internalize the costs of issuing government debt, since if it is not reappointed debt repayment or debt repudiation is not costly for him. Moreover, if $P$ is sufficiently close to 1 , the interest cost due to the risk premium is negligible. As a result, type " $c$ " is better off at $\bar{d}$ than $J^{W}$. By continuity, this argument also applies if $\phi>0$ but small. Conversely, suppose that $\theta^{C}=\theta^{W}$ and $\phi$ is large. Here, it can be shown that $d_{2}=\vec{d}^{-N}$ may be optimal for type $c$. At $\mathrm{d}_{2}=\bar{d}$, the interest rate on external debt is higher because of the risk premium. Moreover, the type " $c$ " government suffers a loss if the the debt is repudiated, since some of the capitalists external assets are 
seized. It can be shown that, if $k_{2}(\bar{d}) \leq k_{2}\left(\bar{d}^{w}\right)$, this loss always exceeds in real terms the additional resources appropriated through the extra borrowing. Hence, if $k_{2}(\bar{d}) \leqq k_{2}\left(\bar{d}^{w}\right)$, type " $c$ " always prefers $\bar{d}^{w}$ relative to $\bar{d}$. If $k_{2}(\bar{d})>k_{2}\left(\bar{d}^{w}\right)$ then the comparison is ambiguous. However, under the hypothes is that $\theta^{C}=\theta^{W}$ and $\phi$ is large, the solution $d_{2}=\partial^{w}$ is more likely. 